\title{
Surveillance of cardiovascular diseases in the Italian adult population
}

Citation for published version (APA):

Palmieri, L. (2013). Surveillance of cardiovascular diseases in the Italian adult population. [Doctoral Thesis, Maastricht University]. Maastricht University. https://doi.org/10.26481/dis.20130228lp

Document status and date:

Published: 01/01/2013

DOI:

10.26481/dis.20130228Ip

Document Version:

Publisher's PDF, also known as Version of record

\section{Please check the document version of this publication:}

- A submitted manuscript is the version of the article upon submission and before peer-review. There can be important differences between the submitted version and the official published version of record.

People interested in the research are advised to contact the author for the final version of the publication, or visit the DOI to the publisher's website.

- The final author version and the galley proof are versions of the publication after peer review.

- The final published version features the final layout of the paper including the volume, issue and page numbers.

Link to publication

\footnotetext{
General rights rights.

- You may freely distribute the URL identifying the publication in the public portal. please follow below link for the End User Agreement:

www.umlib.nl/taverne-license

Take down policy

If you believe that this document breaches copyright please contact us at:

repository@maastrichtuniversity.nl

providing details and we will investigate your claim.
}

Copyright and moral rights for the publications made accessible in the public portal are retained by the authors and/or other copyright owners and it is a condition of accessing publications that users recognise and abide by the legal requirements associated with these

- Users may download and print one copy of any publication from the public portal for the purpose of private study or research.

- You may not further distribute the material or use it for any profit-making activity or commercial gain

If the publication is distributed under the terms of Article $25 \mathrm{fa}$ of the Dutch Copyright Act, indicated by the "Taverne" license above, 
Surveillance of cardiovascular diseases in the Italian adult population

\section{Luigi Palmieri}


(C) Luigi Palmieri, Maastricht 2013

PhD Thesis Maastricht University

Layout: Luigi Palmieri

Cover: Fredericum De Wit, Tabula Italiae, Corsicae, Sardiniae et Adiacentium Regnorum Amstelredami, 1650. San Marco Library, Venice, Italy

Printed by: PIODA editore, Rome, Italy

All rights reserved. No part of this thesis may be reproduced, stored in a retrieval system or transmitted in any form or by any means, without the permission in writing from the author, or, when appropriate, of the publishers of the publications. 


\section{Surveillance of cardiovascular diseases in the Italian adult population}

\section{PROEFSCHRIFT}

ter verkrijging van de graad van doctor

aan de Univarsiteit Maastricht

op gezag van de Rector Magnificus,

Prof. Dr. L.L.G. Soete;

Volgens het besluit van het College van Decanen,

In het openbaar te verdedigen op

Donderdag 28 Februari 2013 om 12.00 uur

door

Luigi Palmieri 


\section{(Co-) Promotores}

Em. Prof. Dr. HC. Hemker, University of Maastricht

Prof. Dr. G. de Gaetano, Campobasso, Italy

\section{Beoordelingscommissie}

Prof. Dr. W. Th. Hermens (Chairman)

Prof. Dr. H.E.J.H. Stoffers

Prof. Dr. M.H. Prins

Prof. Dr. E.E. Blaak

Dr. A.J. ten Cate-Hoek

The research described in this thesis was partially supported by the Progetto CUORE, funded by the Center for Disease Control of the Ministry of Health, Rome, Italy 
To Simona, my enthusiast boss 


\section{Contents}

$\begin{array}{ll}\text { 1. General Introduction } & 11\end{array}$

2. Part one: Population based registers for attack 15 rates and case fatality of coronary and cerebrovascular events

Reference A - The Italian register of cardiovascular disease: attack rates and case fatality for cerebrovascular events

Reference B - Hospital discharge data for assessing myocardial infarction events and trends, and effects of diagnosis validation according to MONICA and AHA criteria

3. Part two: Longitudinal studies for incidence and hazard ratio of coronary and cerebrovascular events

Reference C - Favorable cardiovascular risk profile and 10-year coronary heart disease incidence in women and men: results from the Progetto CUORE

Reference D - Favorable cardiovascular risk profile (low risk) and 10-year stroke incidence in women and men: findings from 12 Italian population samples

4. Part three: Estimation of population based incidence and prevalence of coronary events

Reference E - Estimating population-based incidence and prevalence of major coronary events

Reference $F$ - Incidence and prevalence of ischaemic heart disease in Italy: estimates from the MIAMOD model

5. Part four: Implementation of a surveillance system for CVD risk and possible use of data

Reference G - Cardiovascular risk assessment in Italy: the CUORE project risk score and risk chart 
Reference H - CUORE project: implementation of the 10-year risk score

Reference I - Explaining the decrease in coronary heart 109 disease mortality in Italy between 1980 and 2000

6. General Discussion

121

7. Crucial Issues, Concluding remarks, Recommendations

8. Summary

Samenvatting

149

Riassunto

151

9. Selected Publications

153

10. Curriculum Vitae

155

11. Other publications not cited in the thesis

159

12. Acknowledgments

163 
Cardiovascular disease (CVD) is the leading cause of death and hospitalization in both genders in nearly all countries of Europe. In the European Union $46 \%$ of women and $39 \%$ of men die from CVD. CVD clinically manifests itself in middle life and older age after many years of exposure to unhealthy lifestyles (smoking habit, unhealthy diet, physical inactivity) and risk factors (total and low-density lipoprotein cholesterol, blood pressure, diabetes).

Cardiovascular diseases in general, but cerebrovascular diseases in particular, cause substantial loss of quality of life, disability, and lifelong dependence on health services and medications [1].

For many years CVD mortality has been decreasing in the majority of Western European countries and during recent years mortality has also been decreasing in Eastern Europe. However, the absolute number of patients in need of using health services for CVD conditions does not decrease to the same extent because prevalence tends to increase, due to an increase in survival and an increasing proportion of older people in the population. CVD has major economical consequences as well as human costs.

CVD alone accounts for $20 \%$ of global total DALYs (Disability Adjusted Life Years) in persons older than 30 years. In terms of health, acute events may mean an increasing number of dependent, chronically ill and disabled people: this may cause increasing costs of health care and strain the health care system. Up to $80 \%$ of heart disease, stroke, and type 2 diabetes could be prevented by eliminating shared risk factors, mainly tobacco use, 
unhealthy diet, physical inactivity and the harmful use of alcohol [2].

The favorable position of Italy in terms of coronary heart disease (CHD) and cardiovascular disease has been consistently documented by official mortality statistics and different epidemiological studies $[3,4]$. However, CHD still represents one of the main causes of death in Italy, accounting for $13 \%$ of general mortality and $32 \%$ of circulatory system deaths in the country. Stroke remains a major cause of morbidity, disability, and death worldwide. This situation is particularly true for Italy, where stroke mortality rates have, for decades, been higher than those for most Western countries [5].

The magnitude of the CVD contrasts with the paucity, weak quality and comparability of data available on the main disease indicators of CVD beyond mortality.

Then surveillance, the ongoing systematic collection, analysis, interpretation and dissemination of health information, is essential in measuring the impact of efforts to prevent chronic diseases and in particular CVD.

Surveillance differs both from research studies, which mainly focus on risk factors, events occurrence and prevalence, possible causes of disease studying the relation between risk factors and the occurrence of disease, and routine registration systems (e.g. mortality and hospital discharge records) which give pictures of mortality and morbidity with a low level of reliability not using any kind of validation [6].

The primary purpose of establishing and maintaining a system of surveillance is to provide health workers and policy makers with a 
reliable tool to plan cost-effective strategies to meet the demands for health care and prevention in the population. Surveillance should be focused on diseases that are or are likely to become public health problems. Also, surveillance programmes are more likely to be sustained if they address diseases for which effective control or prevention measures are available.

A surveillance system should include not only a capacity for collection and analysis of data, and dissemination of information, but also direct links to public health programmes.

The aim of this thesis is to show and evaluate the role and evidence of different implemented studies based on different sources of data as basic contribution to build and implement an integrated surveillance system for monitoring CVD and main risk factors in the Italian adult population; the importance of data deriving from different kind of studies as the necessary information to plan and implement preventive actions at population level; some encouraging effects on main CVD indicators obtained from implementation of the preventive actions at population level.

Most of results shown in this thesis are carried out within the CUORE Project on the Italian adult population, in particular from the population-based National Register of Major Coronary and Cerebrovascular Events implemented in 1998-1999, in 2003, and in 2004-2005 to estimate attack rates and case fatality of CVD events; from the Cardiovascular Epidemiologic Observatory/Health Examination Survey (CEO/HES) implemented in 1998-2002 and in 2008-2012 to measure prevalence of main cardiovascular diseases and risk factors; and from the ongoing Cardiovascular Risk 
Observatory (CRO) started in 2006 to provide main indicators on cardiovascular risk and cardiovascular risk factors on the basis of data sent by General Practitioners through a computerized national system. The CUORE Project was launched in 1998, funded by $1 \%$ of the Italian National Health Fund and is coordinated by the Italian National Institute of Health.

Other works cited in this thesis derive from the EUROCISS Project (European Cardiovascular Indicators Surveillance Set), started in 2000 and refunded in 2004 as part of the Health Monitoring Programme, and funded by the European Commission to develop health indicators and recommendations for the monitoring and surveillance of cardiovascular diseases (CVD).

\section{References}

1. Cerebrovasc Dis 2007;24:530-539

2. Lancet $2004 ; 364(9438): 937-52$

3. Eur J Cardiovasc Prev Rehabil 2006;13:562-570

4. Am J Epidemiol 2006;163:893-902

5. WHO Regional Office for Europe 2006 (http://www.WHO.dk/hfadb)

6. Eur J Cardiovasc Prev and Rehab 2007;14(Suppl.3):23-41 


\section{Part one: Population based registers for attack rates and case fatality of coronary and cerebrovascular events}

Although CVD has been identified as one of the leading contributors to the global disease burden, indicators that are considered reliable for monitoring CVD and for which data are available across EU countries are currently limited.

Even mortality, which is probably the only indicator available at national level in all countries, is scarcely comparable since diagnostic criteria for coding death certificates are not defined at international level.

Actually, the most useful recommended indicator for coronary and cerebrovascular events is the attack rate. This indicator provides a lot of information since it considers both first and recurrent, fatal and non-fatal events and is based on a combination of mortality and morbidity data. Attack rates may be derived either from regional population-based registers or national administrative registers which use data from hospital discharges and deaths.

The first manuscript included in this thesis refers to the Italian National Register of Cardiovascular diseases [reference A], a surveillance system of fatal and nonfatal cardiovascular events in the general population aged 35-74 years. The Register was launched in Italy at the end of the 1990s with the aim of estimating periodically the occurrence and case fatality rate of coronary and cerebrovascular events in the different geographical 
areas of the country. The work demonstrates the feasibility of implementing a population-based register using a validated routine database, necessary for monitoring cardiovascular diseases. In particular in the cited work, I was in charge of coordinating the register, and analyzing and elaborating data for coronary and cerebrovascular events. Current events were assessed through record linkage between two sources of information: death certificates and hospital discharge diagnosis records. Events were identified through the ICD codes and duration. To calculate the number of estimated events, current events were multiplied by the positive predictive value (PPV) of each specific mortality or discharge code derived from the validation of a sample of suspected events. Attack rates were calculated by dividing estimated events by resident population, and case fatality rate at 28 days was determined from the ratio of estimated fatal to total events.

Between the late 1990s and the early 2000s more sensitive and specific biomarkers of myocardial necrosis (i.e. troponins) were introduced and new diagnostic criteria, emphasizing the role of biomarkers, have been developed for clinical and epidemiological purposes. In the second manuscript included in this thesis [reference B], the impact of new diagnostic criteria were assessed in the population of Tuscany, a specific region of the Central Italy. 


\section{Reference A}

\section{THE ITALIAN REGISTER OF CARDIOVASCULAR DISEASE: ATTACK RATES AND CASE FATALITY FOR CEREBROVASCULAR EVENTS}

Luigi Palmieri, Alessandro Barchielli, Gian Carlo Cesana, Enrico de Campora, Carlo Alberto Goldoni, Paolo Spolaore, Massimo Uguccioni, Federico Vancheri, Diego Vanuzzo, Paola Ciccarelli, and Simona Giampaoli on behalf of the Research Group of the Project Italian National Register of Coronary and Cerebrovascular Events.

Cerebrovasc Dis 2007; Vol.24, No.6: 530-539 (DOI: 10.1159/000110423) 


\section{Reference B}

\section{HOSPITAL DISCHARGE DATA FOR ASSESSING MYOCARDIAL INFARCTION EVENTS AND TRENDS, AND EFFECTS OF DIAGNOSIS VALIDATION ACCORDING TO MONICA AND AHA CRITERIA}

Alessandro Barchielli, Daniela Balzi, Paola Naldoni, Anna Teresa Roberts, Francesco Profili, Francesco Dima, and Luigi Palmieri.

Journal of Epidemiology and Community Health 2010 online, published on 19th October 2010; $10.1136 /$ jech.2010.110908 


\section{Part two: Longitudinal studies for incidence and hazard ratio of coronary and cerebrovascular events}

Population based Registers mainly provide reliable attack rate and case fatality indicators; rarely, it is possible to elaborate a core indicator such as incidence of coronary and cerebrovascular events. Longitudinal studies represent the proper and most reliable studies for estimating incidence of cardiovascular diseases.

Moreover, by the point of view of the surveillance of cardiovascular diseases as one of the main activities for improving public health, cardiovascular risk factor research has recently broadened its focus based on new data indicating the benefits of low risk, i.e. favorable levels of all major risk factors.

Taking into account these points, the aims of the study included in this thesis [reference C] were to estimate incidence of coronary heart disease in the Italian adult population, to assess further the relation of low risk to coronary heart disease risk, and implications for prevention. Used data derived from the prospective population based Italian study of the Progetto CUORE including 7,438 men and 13,009 women aged 35-69 years with a mean follow-up of 10.4 years; all first coronary events were validated. Baseline coronary heart disease risk was classified into three categories on the basis of risk factors combinations: low risk, unfavorable but not high risk, and high risk. To analyze the relation of these risk profiles to coronary heart disease incidence, were calculated age- 
adjusted, sex-averaged coronary heart disease incidence for persons free of coronary heart disease and stroke, stratified as baseline low risk, unfavorable but not high risk or high risk. To assess the independent relationship of individual risk factors to coronary heart disease incidence, multivariate proportional hazards models for combinations of risk factors were computed.

Most data on low risk relate to coronary heart disease, but not to stroke. Using the population based Italian study (Progetto CUORE, 1983-2002), with 10-year follow-up in 12 samples distributed overall the country, incidence of stroke in the Italian adult population, the relation of low risk to stroke, and implications for prevention were assessed [reference D].

Main results from both analyses, for coronary and stroke events, suggest that population-wide prevention is needed, especially through lifestyles improvement, to increase the proportion of the population at low risk. 


\section{Reference C}

FAVORABLE CARDIOVASCULAR RISK PROFILE AND 10-YEAR CORONARY HEART DISEASE INCIDENCE IN WOMEN AND MEN: RESULTS FROM THE PROGETTO CUORE

Luigi Palmieri, Chiara Donfrancesco, Simona Giampaoli, Michela Trojani, Salvatore Panico, Diego Vanuzzo, Lorenza Pilotto, Gian Carlo Cesana, Marco Ferrario, Paolo Chiodini, Roberto Sega, and Jeremiah Stamler.

Eur J Cardiovasc Prev Rehabil 2006; 13(4): 562-570 


\section{4}




\section{Reference D}

\section{FAVORABLE CARDIOVASCULAR RISK PROFILE (LOW RISK) AND 10-YEAR STROKE INCIDENCE IN WOMEN AND MEN: FINDINGS FROM 12 ITALIAN POPULATION SAMPLES}

Simona Giampaoli, Luigi Palmieri, Salvatore Panico, Diego Vanuzzo, Marco Ferrario, Paolo Chiodini, Lorenza Pilotto, Chiara Donfrancesco, Gian Carlo Cesana, Roberto Sega, and Jeremiah Stamler.

Am J Epidemiol 2006; 163: 893-902 
52 
53 
54 


$$
60
$$


61 
62 


\section{Part three: Estimation of population based incidence and prevalence of coronary events}

Before longitudinal study of the Progetto CUORE data would be available for estimating cardiovascular events incidence, population-based data on coronary events were generally lacking for large areas, such as at the nationwide level. While mortality data are currently and exhaustively collected in all developed countries and in most developing countries, incidence and prevalence are often available only for certain subgroups of the population under study. In order to produce an estimation of coronary events incidence in the Italian adult population, it was conducted a work analysis with the aims of [reference E] reconstructing incidence and prevalence of major coronary events using the official mortality data and survival experience of coronary events provided by the Area Friuli-MONICA (MONItoring of CArdiovascular diseases) register, calculating their projections from 1998 to 2007, and disentangling prevalence trend into its main determinants: population ageing, incidence trend, and survival trend. Incidence and prevalence of major coronary events have been assessed by a statistical model named MIAMOD (Mortality and Incidence Analysis MODel). The model was already applied in Italy at the beginning of the 90 s as a pilot analysis using survival and 3 years incidence from the Area Latina-MONICA Project. It was implemented to estimate population-based incidence and prevalence of coronary events using mortality and survival data as input, and to forecast coronary event occurrence 
using an age, period and cohort approach. The method reconstructs incidence and prevalence of major coronary events in Italy from 1970 to 1997 and projects trends up to the year 2007 using survival data on coronary events from the Area FriuliMONICA Register.

This information is essential to plan and implement actions aimed at improving medical care services, to evaluate the impact of public health interventions as well as spontaneous changing habits. A similar study [reference F] was performed to estimate and forecast incidence and prevalence of coronary events specifically for the three geographical macro areas of the country: northern, central and southern Italy. Using official mortality and population data from national statistics, and survival data on coronary events from the Area Friuli of the MONICA Project, the MIAMOD model was implemented specifically for the Italian geographical macroareas. Incidence was described from 1970 to 1994 and projected to the year 2004; prevalence was reported at 1990 and 2000.

Incidence and prevalence data distributed for northern, central and southern Italy are essential to plan and implement major actions aimed at improving medical care services and to evaluate the impact of public health interventions as well as spontaneous changing habits among the population.

Before results from the first Italian Cardiovascular Epidemiological Observatory (CEO)/Health Examination Survey would be available for estimating cardiovascular diseases prevalence (published in 2003), the MIAMOD Model was applied to estimate prevalence of coronary heart disease in the Italian adult population at both nationwide level and geographical macro area level. 


\section{Reference E}

\section{ESTIMATING POPULATION-BASED INCIDENCE AND PREVALENCE OF MAJOR CORONARY EVENTS}

Simona Giampaoli, Luigi Palmieri, Riccardo Capocaccia, Lorenza Pilotto, Diego Vanuzzo.

International Journal of Epidemiology 2001; 30: S5-S10 
66 
67 
68 
69 


\section{Reference F}

\section{INCIDENCE AND PREVALENCE OF ISCHAEMIC HEART DISEASE IN ITALY: ESTIMATES FROM THE MIAMOD MODEL}

Simona Giampaoli, Luigi Palmieri, Lorenza Pilotto, Diego Vanuzzo.

Italian Heart Journal, May 2001; vol.2, n.5: 349-355 
74 
82 


\section{Part four: Implementation of a surveillance system for CVD risk and possible use of data}

Estimation of the main indicators of cardiovascular diseases needs specific research studies ad hoc; these studies need many resources and are long time and huge funds consuming. Estimation of incidence, prevalence, attack rate and case fatality of cardiovascular diseases and distribution of main risk factors in the general population may represent a starting point to implement preventive actions and to build surveillance systems for the disease in the general population as one of the main objectives of public health.

According to the European guidelines on cardiovascular disease (CVD) prevention, the 10-year global absolute cardiovascular risk assessment (10-CR score) is a first step for the implementation of preventive actions in clinical practice. In Italy, the 10-CR score was developed using data from the Italian longitudinal studies of the Progetto CUORE; it predicts 10-year risk of fatal and non-fatal CVD events on the basis of age, sex, systolic blood pressure, antihypertensive treatment, total and HDL-cholesterol, smoking, diabetes [reference G]. The introduction of $10-C R$ score in clinical practice prompted the Ministry of Health to launch the National Training Program for General Practitioners (GPs) on the use and application of cardiovascular risk charts, offered for free to regions and associations. It includes residential training courses, assessment of $10-\mathrm{CR}$ score in the general population by GPs, collection of risk factors and cardiovascular risk data, and their 
delivery to the National Health Institute-Istituto Superiore di Sanità (ISS). A handbook for the residential training course was published and distributed. The Cardiovascular Risk Observatory (CRO) was developed to monitor the use of $10-\mathrm{CR}$ score in clinical practice. It is a web-accessible tool (http://cuore-iss.cineca.it/) that provides stakeholders (Ministry of Health, Istituto Superiore di Sanità-ISS, Agenzia Italiana del Farmaco and Regions) with a platform to analyze GPs collected data (risk factors and 10-CR), improves quality through self-audit and compare 10-CR assessment at regional and national level.

The Italian national prevention plan 2005-2008 included 10-year cardiovascular risk (10-CR) assessment of the general population aged 35-69 years using the CUORE-Project risk score. GPs were encouraged to collect data on risk factors and $10-\mathrm{CR}$ and to contribute to the Cardiovascular Risk Observatory (CRO). The aim of the work [reference $\mathbf{H}$ ] is to demonstrate feasibility and effectiveness of a surveillance system involving GPs and in particular of $10-\mathrm{CR}$ assessment as a first step to implement primary preventive actions at the individual level.

Data were collected using CUORE.exe software, easily and freely downloadable by GPs from the CUORE Project website (www.cuore.iss.it). CRO provides a web-platform to analyze and compare data on 10-CR and risk factors at regional and national levels with the aim of supporting health policy decision processes. These data demonstrate that $10-\mathrm{CR}$ assessment can be the first step to implement preventive actions in primary care. 


\section{Using surveillance disease indicators to explain decrease in CHD mortality}

The availability of cardiovascular disease indicators elaborated and estimated from different kind of studies (population based register, longitudinal study, survey), and different sources (mortality, hospital discharge records, drug consumption register) are fundamental to have an overall picture of the disease. As a main goal of the surveillance of the disease, it is fundamental to have the chance to summarize all the available scientific information in order to explain main trends of the disease, and then try to forecast possible scenarios in terms of mortality, life-years gained, costs for planning future prevention and treatment strategies.

Following this aim, and in collaboration with professor Simon Capewell of the Department of Public Health of the University of Liverpool, it was applied an epidemiological model (IMPACT) that was successfully used in other countries to examine the decline in CHD mortality in Italy between 1980 and 2000 [reference I]. The favorable position of Italy in terms of coronary heart disease (CHD) and cardiovascular disease has been consistently documented by official mortality statistics and different epidemiological studies. However, CHD still represents one of the main causes of death in Italy, accounting for $13 \%$ of general mortality and $32 \%$ of circulatory system deaths in the country. CHD death rates in Italy have shown profound changes during the second half of the 20th century. After a steep increase in CHD death rates up until the first years of the 1970s, a short plateau occurred during the late 1970s, when a slight decline began and 
has continued until recent years. This has been observed in both men and women. This decline is not easy to explain, but some findings are suggestive.

First, population data collected between 1980 and 2000 in the age range of 35 to 64 years suggest that a substantial decrease in certain cardiovascular risk factors has occurred: smoking prevalence has decreased in men and increased in women, systolic blood pressure mean values fell and an improvement in treatment medications was registered, treatments for hypertension appeared effective in men and much more so in women, and obesity increased slightly in men but decreased in women although mean levels of body mass index remained in the overweight range in both genders.

Second, recent decades have seen a revolution in treatments for established CHD in post-myocardial infarction prevention and in secondary prevention such as effective evidence-based therapies including the use of thrombolysis, coronary artery bypass graft (CABG) surgery, coronary angioplasty and stenting, angiotensinconverting enzyme inhibitors, and the use of statins. Determining the respective contributions of prevention and therapy to falling CHD mortality rates is therefore becoming increasingly important both for understanding past trends and for planning future strategies. The previous application of the cell-based IMPACT model in various industrialized countries helped to demonstrate that the proportion of the CHD mortality rate decrease attributable to reductions in major CHD risk factors between 1980 and 2000 ranged from $44 \%$ to $76 \%$, with a complementary contribution from 
cardiovascular treatments. However, no studies in Mediterranean countries have considered the large changes in mortality rates since 1980, nor have they attempted to quantify the relative contributions from specific therapies and risk factor trends.

In this work, the main aim was to examine the extent to which the decrease in coronary heart disease (CHD) mortality rates in Italy could be explained by changes in cardiovascular risk factors versus the use of medical and surgical treatments. A validated model to combine data on changes in risk factors and uptake and effectiveness of cardiac treatments among adult men and women in Italy between 1980 and 2000 was used. Data sources included results of published trials, meta-analyses, official statistics, longitudinal studies, and national surveys.

These results are becoming increasingly important, both for understanding past trends and for planning future prevention and treatment strategies. 


\section{Reference G}

\section{CARDIOVASCULAR RISK ASSESSMENT IN ITALY: THE CUORE PROJECT RISK SCORE AND RISK CHART}

Simona Giampaoli, Luigi Palmieri, Chiara Donfrancesco, Salvatore Panico, Diego Vanuzzo, Lorenza Pilotto, Marco Ferrario, Gian Carlo Cesana, Amalia Mattiello on behalf of The CUORE Project Research Group.

Italian Journal of Public Health, 2007; Year 5, Vol. 4, N. 2: 102-109 
92 
93 
94 
95 


$$
96
$$


98 


\section{Reference H}

\section{CUORE PROJECT: IMPLEMENTATION OF THE 10-YEAR RISK SCORE}

Luigi Palmieri, Rita Rielli, Luca De Mattè, Chiara Donfrancesco, Paola Ciccarelli, Patrizia De Sanctis Caiola, Francesco Dima, Cinzia Lo Noce, Ovidio Brignoli, Alfredo Cuffari, and Simona Giampaoli.

Eu J Card Prev Rehab, 2011; Vol. 18, Issue 4: 642-649 
101 
102 
103 
104 
105 


\section{Reference I}

\section{EXPLAINING THE DECREASE IN CORONARY HEART DISEASE MORTALITY IN ITALY BETWEEN 1980 AND 2000}

Luigi Palmieri, Katleen Bennett, Simon Capewell, Simona Giampaoli.

American Journal of Public Health, September 2009; Vol. 99, N. 9: 1-9 
111 
113 
114 


\section{General Discussion}

Disease surveillance in a population can be done using many different data sources (Mortality, Hospital Discharge Records, GP Records, Hospital registers, Drug-dispensing registers, Health interview and/or Health examination surveys) and different studies in order to produce main indicators of cardiovascular disease: population based registers for attack rates and case fatality, longitudinal studies for incidence and hazard ratio as a measure of cause relation between main risk factors and events, cross sectional studies such as health examination and/or interview surveys for prevalence of the disease and distribution of main risk factors in the population, case-control studies for odds ratio as a measure of association between events and main risk factors.

Most countries have national databases on causes of death and on discharge diagnoses for hospitalized patients registered according to the International Classification of Disease (ICD) and Causes of Death to make data comparable between countries; in recent years, routine statistics also include discharge diagnoses from hospitalization and, for some countries, visits to outpatient clinics coded according to the same international classifications as the mortality data. These routine statistics are still very important tools for monitoring the disease. Many countries have also some kind of Health Interview Survey or/and Health Examination Survey (HIS/HES). These surveys are primarily used for 
monitoring disease prevalence, prevalence of risk factors (health behavior, social network, environmental risk factors) and of disease consequences (disability, reduced physical function, unemployment).

Few countries have established population disease-specific registers which ensure a more precise and valid monitoring of the disease. The strength of the register lies in the aim of validating each single event according to standardized diagnostic criteria and collecting disease-specific clinical and paraclinical data [1]. The weakness lies in the fact that data collection is expensive and this kind of register can usually be maintained for a limited period of time in a defined population of reasonable size. Another limitation is that a local or regional register may not be representative of the whole country.

\section{References}

1. Acta Med Scand Supplementum 1998;728:26-39 


\section{Population based registers for attack rates and case fatality of coronary and cerebrovascular events}

The Italian population based registers for the surveillance of coronary and cerebrovascular events have been implemented in recent periods of time (1998-99, 2003, 2004-05) in order to estimate attack rates and case fatality rates in the adult resident population. In Italy cerebrovascular attack rates were found to be higher in men than in women, mean age-standardized attack rate was $21.9 / 10,000$ in men and $12.5 / 10,000$ in women; agestandardized 28-day case fatality rate was higher in women $(17.1 \%)$ than in men $(14.5 \%)$. Significant geographical differences were found in attack rates of both men and women. Differences still exist in the geographical distribution of attack and case fatality rates of cerebrovascular events, regardless of the north-south gradient.

In comparison to other previous studies conducted up to now in Italy, results are extremely coherent: for example attack rates of stroke events reported for MONICA Friuli between 1984 and 1989 were $12.4 / 10,000$ for men and $6.1 / 10,000$ for women [1]; these values correspond to similar attack rates of the Italian cerebrovascular register considering the same age range (35-64 years): $12.3 / 10,000$ and $6.3 / 10,000$, respectively.

Population based monitoring of coronary and cerebrovascular events involves a number of problems, the most important being the completeness of case ascertainment. This is especially true for 
population areas where many patients are not diagnosed or treated in hospital.

In recent years, the availability of hospital discharge records and death certificates in electronic format has facilitated the event identification through the record linkage between databases. The Italian register is based on record linkage of administrative data, performed after an accurate quality control of mortality and hospital discharge databases. In addition, this register includes validation which provides the means to:

- avoid biases deriving from different procedures adopted in case history coding in different areas;

- collect extensive information on events, monitor use of treatments, and diagnostic tools;

- ensure data comparability within the register (different subpopulations and different time points);

- ensure data comparability with other registers within the country;

- ensure international comparability.

For what concerns impact of modifications in studied diagnostic criteria, the register of Acute Myocardial Infarction (AMI) implemented in the region of Tuscany showed that attack rates increased from 1997 to 2005 (men: +17\%; women: +30\%); then they decreased in the following two years, (men: -8\%; women: $13 \%)$. The raise of hospitalized AMI was due to cases with ICD9CM code 410.7 (largely representing Non-ST elevation myocardial infarction). According to the AHA criteria, $94.6 \%$ events of sample 1 , and $29.8 \%$ events of sample 2 , fulfilled the most extensive 
criteria for definite, probable or possible AMI. As expected, the more updated AHA definition identified as definite AMI an additional $33.3 \%$ if compared to the MONICA criteria $(86.0 \%$ vs. $52.7 \%)$.

These results are consistent with many studies evaluating the impact of new diagnostic tests and of new case definition criteria on the diagnosis of AMI [2]. Besides, as observed in other studies $[3,4]$, results of discharge diagnosis validation indirectly support the hypothesis that the increasing trend of hospitalized AMI is largely due to the widespread adoption in clinical practice of new diagnostic guidelines and new diagnostic markers. A community study conducted in Minnesota, USA, confirmed that the application of new definitions resulted in a large increase in the number of AMI [5].

Unfortunately for cardiovascular diseases, indicators such as attack rates and case fatality are not available in all countries.

The experience of the Italian National Register of Cardiovascular diseases was fundamental to conduct the EUROCISS Project. In this project, data and information from 14 European countries were collected and an inventory of different available indicators on CVD was built. From this work, it was soon clear that morbidity data are rarely available in the different countries and, when available, they are very rarely comparable [6]. The aims of the $1^{\text {st }}$ phase of the Project, were to list the existing population based registers in Europe, to describe the procedures and methods adopted in order to discuss the comparability of indicators, and to give recommendations for building a surveillance system based on standardized procedures providing valid and comparable data as 
essential tool for evaluating the burden of CVD in Europe and for planning appropriate preventive actions. Adopting such recommendations, in the $2^{\text {nd }}$ phase of the EUROCISS Project, a manual of operations for implementing a population based register of Acute Myocardial Infarction [7], and a manual of operations for implementing a population based register of stroke [8] were developed.

\section{References}

1. Stroke $1997 ; 28: 500-506$

2. Am Heart J $2006 ; 151: 654-60$

3. Eur Heart J 2006;27:2394-2399

4. Am J Epidemiol 2008; $168: 225-33$

5. Circulation $2006 ; 114: 790-797$

6. Eur J Public Health 2003;13(Suppl.3):55-60

7. Eur J Cardiovasc Prev Rehabil 2007;14(Suppl.3):3-22

8. Eur J Cardiovasc Prev and Rehab 2007;14(Suppl.3):23-41 


\section{Longitudinal studies for incidence and hazard ratio of coronary and cerebrovascular events}

The CUORE Project has developed a database of CVD risk factors collected in several Italian longitudinal studies carried out between the mid 1980s and the mid 1990s which followed up total and cause-specific mortality and CVD morbidity in order to assess global absolute risk of CVD for men and women separately and low risk conditions for risk surveillance.

Only $2.7 \%$ of participants aged $35-69$ years, enrolled in the study cohorts, met low risk criteria; $81.4 \%$ were high risk. Age-adjusted coronary heart disease incidence for the whole cohort was 37.1 out of 10,000 person-years (men 59.0; women 15.3). No coronary heart disease events occurred in low-risk men, only two in low-risk women. For women and men who were not high risk, the age-sex standardized coronary heart disease rate was $62 \%$ lower than for high-risk participants. Blood pressure, need for antihypertensive medication, smoking, hyperglycemia, diabetes, total and highdensity lipoprotein cholesterol were independently related to coronary heart disease risk. It was found that favorable levels of all modifiable readily measured risk factors - unfortunately rare among Italian adults - assure minimal coronary heart disease risk.

For what concerns stroke results, at baseline, only $3 \%$ of women and men aged 35-69 years were low risk; $80 \%$ were high risk. Overall, stroke incidence rates were 20.7 for men and 9.6 for women per 10,000 person-years. No strokes occurred in low risk participants, and stroke incidence was low with borderline 
elevation of only one risk factor. Four modifiable risk factors, elevated blood pressure, smoking, diabetes, and high total cholesterol/high density lipoprotein cholesterol ratio were related independently to stroke risk. For those at low risk or who had only one unfavorable (but not high) risk factor, the stroke rate was $76 \%$ lower than for high risk participants; for all persons not at high risk, the stroke rate was 57\% lower than for those at high risk. These results show that favorable risk factor levels assure minimal stroke risk.

In comparison to other international existing risk charts and risk scores derived from the Framingham Study [1], the PROCAM Study [2], the Seven Countries Study [3, 4], and the SCORE project [5], major differences can be found in the availability of data on men and women, the different baseline risk factors, the choice of fatal and non-fatal events as end-points, the possibility to include or not to include stroke as an end-point, and the choice of validating events.

Before the longitudinal study results of the Progetto CUORE would be available, a statistical model named MIAMOD (Mortality and Incidence Analysis MODel), was used to estimate recent years trends of incidence and prevalence of Ischemic Heart Disease in Italy in order to provide forecasts of incidence and prevalence at national and macro-geographical area levels. The MIAMOD method has been mainly used in cancer modeling $[6,7]$, but it resulted well adaptable to other chronic degenerative diseases such as CVD and applied in a previous work relating to Area Latina-MONICA Project [8]. 
In Italy the MIAMOD model was used for estimating projections from 1998 to 2007, and disentangling prevalence trend into its main determinants: population ageing, incidence trend, and survival trend. Major coronary event incidence has been decreasing since 1977 for men and since 1974, for women. Conversely, major coronary event prevalence has continued to increase up to the end of the $80 \mathrm{~s}$ for men and up to the early $80 \mathrm{~s}$ for women, and it has been declining thereafter. Availability of national population data, collection of population based survival data from the MONICA registers and appropriate statistical and mathematical methods help to estimate and project incidence and prevalence trends for major coronary events.

This information, together with incidence and prevalence data distributed for northern, central and southern Italy, is essential to plan and implement major actions aimed at improving medical care services and to evaluate the impact of public health interventions as well as spontaneous changing habits among the population.

In this context, in 1998, the National Health Institute, in collaboration with the Prevention Group of the Italian Association of Hospital Cardiologists, implemented the Italian Cardiovascular Epidemiological Observatory (CEO) / Health Examination Survey (HES) with the aim of estimating prevalence of atherosclerotic cardiovascular diseases, distribution of cardiovascular risk factors and prevalence of risk conditions in the Italian middle-aged population including the control status of the modifiable risk factors [9-11]. 
Fifty-one public hospital Centers were identified, homogeneously spread throughout the country, one every 1.5 million inhabitants, guaranteeing, at any rate, at least one for each region with a lower population and a certain redundancy in the Southern regions, where traditionally data are scanty. Each Centre enrolled 200 resident citizens, 25 per each decennial age and gender (35-44, 45-54, 55-64, and 65-74) randomly selected from the registrar's office. The enrolment was carried out through a personal letter and a phone call. During the survey 9,712 people aged 35-74 years were enrolled, 4,908 men and 4,804 women; 1,267 men and 1,196 women aged 65-74 years; 2,324 menopausal women. Data from interviews and standardized medical examinations and measurements were collected during the survey by health personnel (nurses and doctors) trained during residential theoretical and practical courses; every Center was kept under quality control during the field work.

In 2008 a $2^{\text {nd }}$ survey started using the same standardized methodologies adopted for data collection in the $1^{\text {st }}$ survey in 1998. Twenty centers, one for each region, were selected. The reduction of variability and the improvement of quality control have permitted to reduce the number of centers with respect to the 1998-2002 survey, assuring representativeness for all regions anyway. In each centre, the sample population was extracted from the list of residents. According to CEO recommendations, 220 men and women aged 35-79 years per 1.5 million persons were selected, also in demographically smaller centers. The CEO/HES consented comparison of data collected in the first edition in 19982002 and those collected in the just finished second edition started 
in 2008. Preliminary results on 9 regions, published in Italian language, show that mean level of blood pressure decreased both in men and women of about $3 \mathrm{mmHg}$, as well as prevalence of hypertension. If confirmed by results of all the other regions, this could reflect in a reduction of $23 \%$ of expected strokes and $17 \%$ of AMI in the overall Italian population. Unfortunately total cholesterol, glycaemia, and body mass index increased in the same period of time; prevalence of metabolic syndrome increased, while prevalence of diabetes resulted stable. Prevalence of current smokers continued to decrease in men but not in women.

Starting from the worrying results on the major risk factors distribution in the Italian adult population and considering that also in Mediterranean countries, which are considered a low risk population for cardiovascular disease (CVD), the increasing body mass index (BMI) has become a public health priority, an Italian pilot project with the collaboration of GPs was implemented in January 2006 with the main aim of evaluating the feasibility of a surveillance network for CVD and obesity [12].

Prevalence of overweight was $34 \%$ in women and $50 \%$ in men; prevalence of obesity was $23 \%$ in both men and women. Level of physical activity was mostly low or very low. BMI was inversely associated with consumption of pulses, rotisserie food, chocolate, sweets and physical activity during leisure time and directly associated with consumption of meat. Mean value of total cardiovascular risk, using the Italian CUORE Project risk function, was $4 \%$ in women and $11 \%$ in men. One percent of women and $16 \%$ of men were at high cardiovascular risk ( $\geq 20 \%$ in 10 years). 
Normal weight persons were four times more likely to be at low risk than obese persons.

This study demonstrated the feasibility of a surveillance network of GPs in Italy focusing on obesity and other CVD risk factors. It also provided information on lifestyle habits, such as diet and physical activity.

\section{References}

1. Circulation 1998;97(18):1837-1847

2. Circulation 2002;105:310-315

3. Eur Heart J 2000;21:1639-1642

4. Ann Ital Med Int $2002 ; 17: 81-94$

5. Eur Heart J 2003;24:987-1003

6. Cancer Causes and Control 1995;6:339-346

7. Tumori $1992 ; 78: 13-21$

8. J Clin Epidemiol $1997 ; 50,5: 507-515$

9. Italian Heart Journal 2003;4(Suppl.4):1-122

10. Italian Heart Journal 2004;5(Suppl.3):49-93

11. http://www.cuore.iss.it/eng/factors/oec.asp

12. BMC Family Practice 2008;9:53; doi:10.1186/1471-2296-9-53 


\section{Implementation of a surveillance system for cardiovascular}

risk

The availability of a tool for the assessment of individual cardiovascular risk based on data from Italian adult population cohorts permitted the implementation of a surveillance system based on the assessment of 10-year risk of fatal and non-fatal CVD events $(10-C R)$ in primary prevention in the general population aged 35-69 years. The Italian national prevention plan 2005-2008 included 10-year cardiovascular risk assessment of the general population aged 35-69 years using the CUORE project risk score and General practitioners (GPs) were encouraged to collect data on risk factors and $10-\mathrm{CR}$ and to contribute to the Cardiovascular Risk Observatory (CRO).

Data were collected using the CUORE.EXE software, easily and freely downloadable by GPs from the CUORE project website (www.cuore.iss.it) and sent to the CRO website. CRO provides a web platform to analyze and compare data on 10-CR and risk factors at regional and national levels with the aim of supporting health policy decision processes.

From January 2007 to May 2010, 2.858 GPs downloaded cuore.exe; 139,269 10-CR assessments on 117,345 persons were sent to the CRO. Mean 10-year cardiovascular risk was $3.0 \%$ in women, $8.3 \%$ in men; $30 \%$ of men and $65 \%$ of women were at low risk $(10-\mathrm{CR}<3 \%), 9.2 \%$ of men and $0.4 \%$ of women were at high risk $(10-C R \geq 20 \%)$. Among those with at least two risk assessments $(n=5,948), 8 \%(95 \%-$ C.I. $7 \%-9 \%)$ shifted to a lower risk class after one year. Systolic blood pressure mean levels 
decreased by $1.6 \mathrm{mmHg}$ (95\%-C.I. $1.2-2.1 \mathrm{mmHg}$ ), diastolic blood pressure by $0.9 \mathrm{mmHg}(95 \%$-C.I. $0.5-1.3 \mathrm{mmHg})$, total cholesterol by $5.6 \mathrm{mg} / \mathrm{dl}(95 \%-C . I .4 .3-6.8 \mathrm{mg} / \mathrm{dl})$, and smokers prevalence by $3.5 \%$ (95\%-C.I. 2.5\%-4.6\%); HDL-cholesterol increased in women by $1 \mathrm{mg} / \mathrm{dl}$ (95\%-C.I. 0.5-1.4 mg/dl).

Although data are derived from a non-representative sample of 1,032 GPs, it appears evident that risk can be reduced and maintained low despite age increase and counseling advices may be well received. Among men and women followed-up by GPs, statistically significant reductions of systolic and diastolic blood pressure, total cholesterol, and prevalence of smokers have been registered; moreover, results suggest an improvement in hypertension and hypercholesterolemia control.

Some studies demonstrate how a physician-implemented cardiovascular risk evaluation and communication programme improves patients' modifiable risk factor profile and lowers predicted risk compared with usual care; they give also evidence for the efficacy of an intervention addressing multiple risk factors for primary prevention at 1 year using risk scores and counseling or treatment interventions [1-4].

These data demonstrate the feasibility of a surveillance system based on 10-year CVD risk assessment as a first step to implement preventive actions in primary care.

\section{References}

1. Int J Clin Pract 2008;62(10):1484-1498

2. BMC Med 2010;8:29

3. CMAJ 2007;177(8):859-865

4. Med Decis Making 2000;20(3):290-297 


\section{Using surveillance disease indicators to explain decrease in CHD mortality}

It is possible to use available cardiovascular disease indicators elaborated and estimated from different kind of studies (population based register, longitudinal study, survey), and different sources (mortality, hospital discharge records, drug consumption register) to explain main trends of Coronary Heart Disease mortality. These data are fundamental to forecast possible scenarios in terms of mortality, life-years gained, and costs for planning future prevention and treatment strategies.

To examine the contributions of various factors to the changes in CHD mortality rates among Italian adults aged from 25 to 84 years, it was used an updated version of the IMPACT mortality model, which has been previously validated in Europe, New Zealand, the United States, and China [1-6].

The difference between observed and expected CHD deaths in 2000 was partitioned among treatments and risk factors. From 1980 to 2000, the age-adjusted CHD mortality rate in Italy fell among persons aged from 25 to 84 years, resulting in 42,930 fewer CHD deaths in 2000. Approximately $40 \%$ of this decrease was attributed to treatments and $55 \%$ to changes in risk factors. Over half of the CHD mortality fall in Italy between 1980 and 2000 was attributable to reductions in major risk factors, mainly cholesterol and blood pressure, and less than half to evidencebased medical therapies. 
All modeling analyses have limitations and should be interpreted with appropriate caution. All require the gathering of data from numerous sources, each with recognized shortcomings. Therefore, it was necessary sometimes to use data from studies possibly constrained by geographic, ethnic, or selection bias or extrapolate to older age groups. For instance, results from 2 different studies were used to estimate cholesterol levels at the beginning and at the end of the study period [7-9] and changes in laboratory methods, equipment, and reagents for cholesterol assay also occurred over the last 20 years. Variations from different study designs and study periods could potentially influence results. Even though unpublished original data were used together with published ones, publication bias exists. However, the results were reasonably consistent in a series of sensitivity analyses.

These results are becoming increasingly important, both for understanding past trends and for planning future prevention and treatment strategies.

\section{References}

1. Heart $1999 ; 81: 380-386$

2. Circulation $2000 ; 102: 1511-1516$

3. Circulation 2004;109:1101-1107

4. BMJ $2005 ; 331: 614$

5. Am J Epidemiol $2005 ; 162: 764-773$

6. Circulation 2004;110:1236-1244

7. G Ital Cardiol $1995 ; 25: 1539-1572$

8. Ital Heart J 2004;5(Suppl.3):1-101

9. Ital Heart J 2004;5(Suppl.8):19-27 


\section{Crucial Issues, Concluding Remarks, Recommendations}

The aim of this thesis was to evaluate the importance of implementing different studies based on different sources of data to build and maintain an integrated surveillance system for monitoring CVD and main risk factors in the Italian adult population; to evaluate the role of data deriving from different kind of studies as the necessary information to plan and implement preventive actions at population level; to demonstrate that preventive actions implemented at population level can produce encouraging effects on main CVD risk factors and CVD indicators.

\section{In this regard some crucial issues have been discussed:}

\section{- How is possible to produce a reliable and comprehensive picture of CVD in the population?}

General mortality and cause specific mortality are not sufficient to give an overall picture of CVD at population level. In addition, other specific indicators are necessary to describe a chronic disease such as CVD. In Italy, specific studies have been implemented in order to produce basic, reliable, comparable, and representative indicators: population based registers to obtain attack rates and case fatality rates for coronary and cerebrovascular events; longitudinal studies to obtain incidence of CVD; health examination survey to obtain distribution and 
prevalence of main CVD and cardiovascular risk factors and conditions.

\section{- Which characteristics should the studies producing reliable indicators for CVD as far as possible respect?}

Reliability and representativeness are crucial issues in the studies implemented to assess main indicators of CVD. For representativeness, it is internationally accepted by the long experience derived from cancer registers that it is not necessary to include the overall national population in order to have an estimate of the occurrence of the disease. In the Italian national register of CVD events about 5 millions of resident population aged 35-74 years, out of about 35 millions, was under surveillance for CVD events in 8 areas overall the country in the two-year periods 199899 and 2004-05.

For reliability, validation of events following international diagnostic criteria is crucial. Even though starting from the merging between official mortality and Hospital Discharge Records, the simplified methodology adopted in the Italian national register of CVD events included the validation, according to the international diagnostic criteria of the MONICA project, of a sample of 2000 coronary and cerebrovascular events for each area in the 2-year period. This choice needed a very huge work for the collection of all necessary information from the hospital charts of the hospitalized fatal and non fatal events to be validated, and from interviews of families or GPs for fatal non-hospitalized events. Longitudinal studies included more than 20 thousand men and women of general population aged 35-69 years in the North, Center and South of Italy. All coronary and cerebrovascular events 
were validated according to the MONICA criteria, and all risk factors and conditions were assessed following international standardized methodologies.

The same international standardized methodologies were followed to collect all risk factors and conditions included in the Cardiovascular Epidemiologic Observatory/Health Examination Survey implemented on a sample of about 10 thousand men and women aged 35-74 years distributed in 53 centers overall the country in 1998-2002, and about 10 thousand men and women aged 35-79 years distributed in 22 center, at least 1 center in each region, in 2008-2012.

\section{- Is it possible to use different source of information to estimate and forecast main epidemiological indicators for CVD?}

To estimate incidence and prevalence of CVD, longitudinal studies and cross sectional surveys are the most appropriate; these kind of study are very expensive and time consuming to be implemented at population level. The use of specific mathematical and statistical models helps to solve such issue. Starting from population data, mortality data and survival data on coronary events from the population based register of the Area FriuliMONICA, the MIAMOD model helped to reconstruct incidence and prevalence of major coronary events in Italy from 1970 to 1997, and to project trends up to the year 2007. Moreover, it was possible to disentangle prevalence trend into its main determinants: population ageing, incidence trend, and survival trend to better investigate secular trends. 
On the other side, availability of cardiovascular disease indicators, risk factors distributions, and specific surgical and medication treatments in primary and secondary prevention, evaluated and estimated from different kind of studies and different sources of information at national level, can be used to explain mortality trends of the disease in wide ranges of time. The validated IMPACT model applied to Italian data estimated the contribution of $55 \%$ out of about 43.000 Coronary heart Diseases deaths prevented or postponed between 1980 and 2000; 40\% was the contribution from overall specific treatments. Starting from consolidated data, this kind of model can help to forecast possible scenarios in terms of mortality, life-years gained, costs for planning future prevention and treatment strategies.

\section{- Is it possible to use results from specific studies to build and implement a surveillance system on CVD risk?}

In Italy, the cardiovascular risk, 10-CR score, was developed using data from the Italian longitudinal studies of the Progetto CUORE; it predicts 10-year risk of fatal and non-fatal CVD events on the basis of 8 main risk factors (age, sex, systolic blood pressure, antihypertensive treatment, total and HDL-cholesterol, smoking, diabetes). This result gave the opportunity to introduce CVD risk assessment in clinical practice at population level in order to monitor CVD risk and main risk factor in the adult population in primary prevention. Ministry of Health launched the National Training Program for General Practitioners on the use and application of cardiovascular risk charts, which was coordinated and performed by the National Institute of Health-Istituto Superiore di Sanità (ISS) in accordance with Regions. The ISS built 
a specific tool, the software CUORE.EXE, freely downloadable by GPs from the web site of the Progetto CUORE, and a specific web site where all data sent by GPs were collected and analyzed, the Cardiovascular Risk Observatory (CRO), to monitor the use of 10$\mathrm{CR}$ score in clinical practice and to provide stakeholders (Ministry of Health, Istituto Superiore di Sanità-ISS, Agenzia Italiana del Farmaco and Regions) with a platform to analyze GPs collected data, improves quality through self-audit, and compare 10-CR assessment at regional and national level. Results from the CRO demonstrate feasibility and effectiveness of the ongoing surveillance system on cardiovascular risk in Italy involving GPs and, in particular, suggest the assessment of the cardiovascular risk as a first step to implement primary preventive actions at individual level. 


\section{Concluding Remarks}

The assessment of an updated and integrated picture of the occurrence (National Register of Cardiovascular Events), incidence (longitudinal studies), and prevalence (MIAMOD model studies) of main cardiovascular diseases by one sight, and the evaluation of distribution of main risk factors and conditions (CEO/HES studies) deriving by the different studies described through the publications cited in this thesis, confirm that cardiovascular diseases remain a priority for health in the Italian population, even though important improvements have been obtained in recent periods (CHD mortality reduction between 1980 and 2000 explained using the IMPACT model).

Results deriving from different kind of studies represent the necessary information to plan and implement actions focused on primary prevention of cardiovascular diseases in the adult population. Contributions deriving from all the components of the National Health System and overall collaboration are fundamental to obtain remarkable improvements on population health.

The implementation of health professional networks involving General Practitioners, deep-rooted in the national territory and in the general population, demonstrates the feasibility of CVD surveillance in order to take under control main trends of the disease and main risk factors, and then to forecast possible scenarios in terms of mortality, life-years gained, and costs for planning future prevention and treatment strategies. 
This thesis contributes to show the role and evidence of different studies which can contribute to build and implement an integrated surveillance system for monitoring CVD and main risk factors in the Italian adult population. 


\section{Recommendations}

A surveillance integrated system, considered as the ongoing systematic collection, analysis, interpretation and dissemination of health information, is essential in measuring the impact of efforts to prevent chronic diseases and specifically CVD.

The primary purpose of establishing and maintaining a system of surveillance is to provide health workers and policy makers with a reliable tool to plan cost-effective strategies to meet the demands for health care and prevention in the population.

Surveillance should be focused on diseases that are or are likely to become public health problems. Also, surveillance programmes are more likely to be sustained if they address diseases for which effective control or prevention measures are available.

A surveillance system should include not only a capacity for collection and analysis of data, and dissemination of information, but also direct links to public health programmes

The availability of cardiovascular disease indicators elaborated and estimated from different kind of studies (population-based register, longitudinal study, survey), and different sources (mortality, hospital discharge records, drug consumption register) are fundamental to have an overall picture of the disease. 
A surveillance integrated system, considered as the ongoing systematic collection, analysis, interpretation and dissemination of health information, is essential in measuring the impact of efforts to prevent chronic diseases and specifically Cardiovascular Diseases.

The assessment of an updated and integrated picture of the occurrence (National Register of Cardiovascular Events), incidence (longitudinal studies), and prevalence (MIAMOD model studies) of main cardiovascular diseases by one sight, and the evaluation of distribution of main risk factors and conditions (CEO/HES studies) deriving by the different studies described through the publications cited in this thesis, confirm that cardiovascular diseases remain a priority for health in the Italian population, even though important improvements have been obtained in recent periods (CHD mortality reduction between 1980 and 2000 explained using the IMPACT model).

The primary purpose of establishing and maintaining a system of surveillance is to provide health workers and policy makers with a reliable tool to plan cost-effective strategies to meet the demands for health care and prevention in the population. 


\section{Samenvatting}

Een surveillance geïntegreerd systeem, beschouwd als het permanent en systematisch verzamelen, analyseren, interpreteren en verspreiden van informatie over gezondheid, is essentieel bij het meten van de impact van de inspanningen om chronische ziekten te voorkomen en in het bijzonder hart-en vaatziekten.

De beoordeling van een geactualiseerd en geïntegreerd beeld van de attack rate en case-fatality (Nationaal Register van cardiovasculaire gebeurtenissen), de incidentie (longitudinale studies), en de prevalentie (MIAMOD model studies) van de belangrijkste hart-en vaatziekten aan de ene kant, en de evaluatie van de distributie van de belangrijkste risicofactoren (CEO/HES studies) gevonden in de verschillende studies en beschreven in de publicaties geciteerd in dit proefschrift, bevestigen dat hart-en vaatziekten een prioriteit blijven voor de gezondheid in de Italiaanse bevolking, ook al zijn er belangrijke verbeteringen verkregen in de afgelopen periode ( $\mathrm{CHZ}$ sterfte verminderd tussen 1980 en 2000 gemeten door middel van IMPACT-model).

Het primaire doel van het opzetten en onderhouden van een surveillance systeem heeft tot bevoorraden gezondheidswerkers en beleidsmakers te een betrouwbaar hulpmiddel te plannen om kosteneffectieve strategieën om te voldoen aan eisen voor gezondheidszorg en preventie in de bevolking. 


\section{Riassunto}

Un sistema di sorveglianza integrato, considerato come la raccolta sistematica e continua, I'analisi, l'interpretazione e la diffusione di informazioni sulla salute, è essenziale per misurare l'impatto degli sforzi per prevenire le malattie croniche, in particolare le malattie cardiovascolari.

La valutazione di un quadro aggiornato e integrato del tasso di attacco e di letalità (Registro Nazionale degli Eventi Cardiovascolari), dell'incidenza (studi longitudinali), e della prevalenza (studi su modelli MIAMOD) delle principali malattie cardiovascolari da una parte, e la valutazione della distribuzione dei fattori e delle condizioni di rischio più importanti (gli studi OEC/HES) derivanti dai vari studi descritti nelle pubblicazioni citate in questa tesi, confermano che le malattie cardiovascolari rimangono una priorità per la salute nella popolazione italiana, anche se miglioramenti significativi sono stati ottenuti nel periodo recente (riduzione della mortalità per malattie cardiovascolari tra il 1980 e il 2000 spiegata con il modello IMPACT).

Lo scopo principale di impiantare e mantenere un sistema di sorveglianza è quello di fornire agli operatori sanitari e ai decisori politici uno strumento affidabile per pianificare strategie efficaci per soddisfare la richiesta di assistenza sanitaria e di prevenzione nella popolazione. 
152 
A. Palmieri L, Barchielli A, Cesana GC, de Campora E, Goldoni CA, Spolaore $P$, Uguccioni $M$, Vancheri $F$, Vanuzzo D, Ciccarelli $P$, and Giampaoli $S$ on behalf of the Research Group of the Project Italian National Register of Coronary and Cerebrovascular Events. The Italian Register of Cardiovascular Disease: attack rates and case fatality for cerebrovascular events. Cerebrovasc Dis 2007; Vol.24, No.6: 530-539 (DOI: 10.1159/000110423);

B. Barchielli A, Balzi D, Naldoni P, Roberts AT, Profili F, Dima F, and Palmieri L. Hospital discharge data for assessing myocardial infarction events and trends, and effects of diagnosis validation according to MONICA and AHA criteria. Journal of Epidemiology and Community Health, $19^{\text {th }}$ October 2010: 1-6; 10.1136/jech.2010.110908;

C. Palmieri L, Donfrancesco C, Giampaoli S, Trojani M, Panico S, Vanuzzo D, Pilotto L, Cesana G, Ferrario M, Chiodini P, Sega R, and Stamler J. Favorable cardiovascular risk profile and 10-year coronary heart disease incidence in women and men: results from the Progetto CUORE. Eur J Cardiovasc Prev Rehabil 2006 13: 562-570;

D. Giampaoli S, Palmieri L, Panico S, Vanuzzo D, Ferrario M, Chiodini P, Pilotto L, Donfrancesco C, Cesana G, Sega R, and Stamler J. Favorable Cardiovascular Risk Profile (Low Risk) and 10-Year Stroke Incidence in Women and Men: Findings from 12 
Italian Population Samples. Am J Epidemiol 2006; 163: 893902;

E. Giampaoli S, Palmieri L, Capocaccia R, Pilotto L, Vanuzzo D. Estimating population-based incidence and prevalence of major coronary events. International Journal of Epidemiology 2001; 30: S5 - S10;

F. Giampaoli S, Palmieri L, Pilotto L, Vanuzzo D. Incidence and prevalence of ischaemic heart disease in Italy: estimates from the MIAMOD model. Italian Heart Journal, May 2001; vol.2, n.5: 349-355;

G. Giampaoli S, Palmieri L, Donfrancesco C, Panico S, Vanuzzo D, Pilotto L, Ferrario M, Cesana G, Mattiello A, on behalf of The CUORE Project Research Group. Cardiovascular risk assessment in Italy: the CUORE Project risk score and risk chart. Italian Journal of Public Health, 2007; Year 5, Vol. 4, N. 2: 102-109;

H. Palmieri L, Rielli R, Demattè L, Donfrancesco C, Ciccarelli P, De Sanctis Caiola P, Dima F, Lo Noce C, Brignoli O, Cuffari A, and Giampaoli S. CUORE Project experience: implementation of the 10 year risk score. Eu J Card Prev Rehab, 2011; Vol. 18, Issue 4: 642-649;

I. Palmieri L, Bennett K, Giampaoli S, Capewell S. Explaining the Decrease in Coronary Heart Disease Mortality in Italy between 1980 and 2000. American Journal of Public Health, September 2009; Vol. 99, N. 9: 1-9. 
Place and date of birth

Luigi Palmieri was born in Rome, Italy, on the $18^{\text {th }}$ of August 1961

\section{Education}

He attended the Faculty of 'Statistic and Economic Sciences' of the University of Rome "La Sapienza" and in 1997 he discussed a thesis in the field of Methodological Statistics (Title: "Structure and dynamic of balance and operational indicators of the main air flight European companies: an approach based on statistical multiway methods ".

On 1999 he attended the international epidemiological course organized by the International Epidemiological Association (IEA): European Educational Programme in Epidemiology (EEPE) $-12^{\text {th }}$ Residential summer course; Florence, Italy.

On 2002 he attended the $35^{\text {th }}$ Ten-Day Teaching Seminar on Cardiovascular Disease Epidemiology and Prevention - World Heart Federation'; Trivandrum, India.

On 2003 he attended the international course 'Categorical data analysis' and 'Analysis of longitudinal studies' organized by the Mediterranean School of Epidemiology and Statistical methods in Biomedical Research; Siracuse, Italy.

On 2010 he attended the $1^{\text {st }}$ European Health Examination Survey Training Seminar organized by the National Institute for Health and Welfare (THL-Helsinki) Department of Chronic Disease Prevention Chronic Disease Epidemiology and Prevention Unit; Rome, Italy.

On 2010 he attended the $2^{\text {nd }}$ European Health Examination Survey Training Seminar organized by the National Institute for Health and Welfare (THL-Helsinki) Department of Chronic Disease Prevention Chronic Disease Epidemiology and Prevention Unit; Helsinki, Finland. 


\section{Experience}

Since 1998 he attended the Unit of Epidemiology of Cerebro and Cardiovascular Diseases of the National Centre of Epidemiology, Surveillance and Promotion of Health of the National Institute of Health-Istituto Superiore di Sanità (ISS), where he started his scientific career as statistician and epidemiologist in the field of epidemiology of cardiovascular disease and he performed the work of this thesis.

He is involved in several epidemiological studies:

Investigator of the EUROCISS project (Cardiovascular Indicators Surveillance Set) ( $1^{\text {st }}$ edition from 2000 to 2003, $2^{\text {nd }}$ edition from 2004 to 2007): the project, involving 14 EU countries (Austria, Belgium, Finland, France, Germany, Italy, The Netherlands, Norway, Portugal, Spain, Sweden, UK, Denmark and Greece), aimed to evaluate the distribution and the impact of CVD in Europe in order to facilitate comparison among countries and improve prevention and control of CVD. The project was funded by the European Commission in the framework of the Health Monitoring Programme.

He is principal investigator of the Italian National Register of the Coronary and Cerebrovascular events;

Principal Investigator of the Progetto CUORE - Istituto Superiore di Sanità (ISS) - Epidemiology and prevention of ischaemic heart disease ( $1^{\text {st }}$ edition from 2006 to $2008,2^{\text {nd }}$ edition from 2008 to 2010). The project included the implementation of the National register of Coronary and Cerebrovascular Events; the assessment of distribution of main cardiovascular diseases and risk factors through the health examination survey of the Cardiovascular Epidemiologic Observatory (CEO); the assessment of cardiovascular risk function for the Italian adult population through the longitudinal studies; the implementation of the estimated cardiovascular risk charts on the Italian adult population in primary prevention involving General Practitioners and health professional. The project was funded by the Minister of Health.

Work Package leader of the WP-3 'Evaluation of the joint action' of the EU Commission Project 'European Health Examination SurveyJoint Action' (2008-2009). The project, coordinated by the THLNational Institute for Health and Welfare (Finland), involved 14 European Countries to implement, in a pilot sample, the Health 
Examination Survey in each Partners country adopting the same standardized methodologies. The project was funded by European Commission in the framework of the Health Monitoring Programme (Grant agreement $n^{\circ}$ 2009-23-01).

From 2011 is in charge for Italy of the Working Package 5 of the EuroHeart II - European Heart Health Strategy II (agreement $\mathrm{n}^{\circ}$ 20101204) coordinated by the European Health Network (EHN). The aim of the WP is to update the national IMPACT Model for each partner country to explain CHD trend from 2000 to 2010 and forecast CHD trend in the following 20 years. The project included in the Second Programme of the Community in the Field of Health (2008-2013) is funded by the Executive Agency for Health and Consumers of the European Commission.

The principal aim of Dr. Palmieri is to collaborate to implement surveillance systems on cardiovascular diseases at population level. He works on the evaluation, at population level, of cardiovascular events occurrence, cardiovascular risk assessment, distribution of cardiovascular risk factors and conditions associated with lifestyle and dietary habits. 
158 


\section{Other publications not cited in the thesis}

1. Giampaoli S, Palmieri L, Mattiello A, et al. Definition of high risk individuals to optimise strategies for primary prevention of cardiovascular diseases. Nutrition, Metabolism, and Cardiovascular Disease 2005; 15: 79-85;

2. Ferrario $M$, Chiodini $P$, Chambless LE, Cesana GC, Vanuzzo D, Panico S, Sega R, Pilotto L, Palmieri L, Giampaoli S for the CUORE Project Research Group. Prediction of coronary events in a low incidence population. Assessing accuracy of the CUORE Cohort Study prediction equation. Int J Epidemiol. 2005; 34: 413-421;

3. Giampaoli S, Palmieri L, Greco D, et al. The Italian CUORE Project: An alliance among Institutions, Cardiologists and General Practitioners to estimate the global absolute cardiovascular risk assessment and improve heart health in the Italian population. Prevention Update - ESC Congress 2005, Sept. 2005; 4: 8;

4. Scuteri A, Palmieri L, Lo Noce $C$, et al. Age-related changes in cognitive domains. A population-based study. Aging Clinical and Experimental Research, October 2005; 17; 5: 367-373;

5. Giampaoli S, Palmieri L, Donfrancesco C, et al. on behalf of The CUORE Project Research Group. Cardiovascular risk assessment in Italy: the CUORE Project risk score and risk chart. Italian Journal of Public Health, 2007; Year 5, 4; 2: 102-109;

6. The Emerging Risk Factors Collaboration: analysis of individual data on lipid, inflammatory and other markers in over 1.1 million participants in 104 prospective studies of cardiovascular diseases. The Emerging Risk Factors Collaboration. Eur J Epidemiol, 2007; 22(12): 839-869. Epub 2007 Sep 18;

7. Panico S, Palmieri L, Donfrancesco $C$, et al. Preventive potential of body mass reduction to lower cardiovascular risk: the Italian Progetto CUORE Study. Preventive Medicine 2008; 47: 53-60; 
8. Giampaoli S, Palmieri L, Ciccarelli $\mathrm{P}$, et al. Atherosclerotic Cardiovascular Diseases: Ischaemic Heart Disease and Stroke. In MAJOR AND CHRONIC DISEASES REPORT 2007 by the Task Force on Major and Chronic Diseases of DG SANCO's Health Information Strand; Luxembourg: European Commission 2008, pp.305; ISBN 92-79-08896-4; http://ec.europa.eu/health/ph_threats/non_com/docs/mcd_r eport_en.pdf;

9. EUGLOREH Project. The status of health in the European Union: towards a healthier Europe - Report. EU Commission. March 2009: 1-86. (Expert Contribution);

10. Giampaoli S, Stamler J, Donfrancesco C, Panico S, Vanuzzo D, Cesana G, Mancia G, Pilotto L, Mattiello A, Chiodini P, and Palmieri $\mathbf{L}$ for the Progetto CUORE Research Group. The metabolic syndrome: A critical appraisal based on the CUORE epidemiologic study; Preventive Medicine, June 2009; 48(6): 525-31;

11. The Emerging Risk Factors Collaboration, Erqou S, Kaptoge S, et al. Lipoprotein(a) concentration and the risk of coronary heart disease, stroke and nonvascular mortality. JAMA 2009; 302 (4): 412-423;

12. The Emerging Risk Factors Collaboration. Major Lipids, Apolipoproteins, and Risk of Vascular Disease. JAMA 2009; 302 (18): 1993-2000;

13. Asplund K, Karvanen J, Giampaoli S, et al. for the MORGAM Project*. Relative risks for stroke by age, sex and population based on follow-up of 18 European populations in The MORGAM Project. Stroke 2009; 40: 2319-2326;

14. The Emerging Risk Factors Collaboration. C-reactive protein concentration and risk of coronary heart disease, stroke, and mortality: an individual participant meta-analysis. Lancet 2010; Vol. 375, Issue 9709: 132-140;

15. Donfrancesco C, Palmieri L, Cooney $\mathrm{M}-\mathrm{T}$, et al. Italian cardiovascular mortality charts of the CUORE Project: are they comparable with the SCORE charts? Eur J Cardiovasc Prev Rehabil. 2010 Aug; 17(4): 403-9;

16. Rubattu S, Barbato A, Marchitti S, Iacone R, Di Castro S, Evangelista A, Stanzione R, Ippolito R, Sciarretta S, Palmieri L, Volpe M, Strazzullo P on behalf of the Olivetti Heart Study Research Group. Determinants of $\mathrm{N}$-terminal proatrial 
natriuretic peptide plasma levels in a survey of adult male population from Southern Italy. J Hypertens. 2010 Aug;28(8):1638-45;

17. Triglyceride Coronary Disease Genetics Consortium and Emerging Risk Factors Collaboration. Triglyceride-mediated pathways and coronary disease: collaborative analysis of 101 studies. Lancet 2010; 375: 1634-1639;

18. Fornari C, Donfrancesco C, Riva MA, Palmieri L, Panico S, Vanuzzo D, Ferrario MM, Pilotto L, Giampaoli S and Cesana G. Social status and cardiovascular disease: a Mediterranean case. Results from the Italian Progetto CUORE cohort study. BMC Public Health 2010; 10: 574;

19. Borglykke A, Andreasen AH, Kuulasmaa K, Sans $S$, Ducimetière $P$, Vanuzzo $D$, Ferrario $M M$, Palmieri $L$, Karvanen J, Tunstall-Pedoe $H$, Jørgensen $T$ on behalf of the MORGAM Project. Stroke risk estimation across nine European countries in the MORGAM project. Heart 2010;96:1997-2004;

20. The Emerging Risk Factors Collaboration. Diabetes Mellitus, Fasting Glucose, and Risk of Cause-Specific Death. N Engl J Med 2011; 364:829-841;

21. The Emerging Risk Factors Collaboration. Separate and combined associations of body-mass index and abdominal adiposity with cardiovascular disease: collaborative analysis of 58 prospective studies. Lancet, March 2011; 377: 108595;

22. Bodenant $\mathbf{M}$, Kuulasma $\mathrm{K}$, Wagner $\mathrm{A}$, Kee $\mathbf{F}$, Palmieri $\mathbf{L}$, et al. for the MORGAM Project. Measures of Abdominal Adiposity and the Risk of Stroke: The MOnica Risk, Genetics, Archiving and Monograph (MORGAM) Study. Stroke, 2011; 42: published online August 11, 2011;

23. Rapsomaniki E, White IR, Wood AM, Thompson SG, and Emerging Risk Factors Collaboration. A framework for quantifying net benefits of alternative prognostic models; Statistics in Medicine 2011, Sept 9, Published online in Wiley Online Library, (wileyonlinelibrary.com) DOI: 10.1002/sim.4362;

24. Donfrancesco C, Ippolito R, Lo Noce C, Palmieri L, et al. Excess dietary sodium and inadequate potassium intake in Italy: Results of the MINISAL study. Nutr Metab Cardiovasc 
Dis. 2012 Jul 24, doi:10.1016/j.numecd.2012.04.004 [Epub ahead of print];

25. Emerging Risk Factors Collaboration, Kaptoge $S$, Di Angelantonio $E$, Pennells $L$, et.al. C-reactive protein, fibrinogen, and cardiovascular disease prediction. $\mathrm{N}$ Engl J Med. 2012 Oct 4; 367(14): 1310-20;

26. Kuulasmaa $K$, Tolonen $H$, Koponen $P$, Kilpeläinen $K$, Avdicová M, Broda G, Calleja N, Dias C, Gösswald A, Kubinova R, Mindell J, Männistö S, Palmieri L, Tell GS, Trichopoulou A and Verschuren WMM. An overview of the European health examination survey pilot joint action. Archives of Public Health 2012, 70:20 Page 2 of 5; http://www.archpublichealth.com/content/70/1/20. 


\section{Acknowledgements}

My profound thanks and gratitude to Dr. Simona Giampaoli, my guide from ever, my counselor and support in my work; always generous, active, and enthusiast in her work and life.

Warmest thanks to my colleagues Chiara, Franco, and Cinzia without whom my daily work would be unthinkable, my few successes would be of any avail and desolate, and my failures would be impossible to overcome.

To Prof. Jeremiah Stamler, a founder in work and exemplar in life; he never made me suffer his overwhelming excellence in scientific knowledge and culture; he is for me an example to follow.

My grateful thanks to Prof. Giovanni de Gaetano for helping me to make all this possible, and for his competent and generous guidance.

My warmest gratitude to Dr. Licia Iacoviello for her friendly and essential support.

To Franco, who unselfishly, generously, and enthusiastically put his brilliant artistic ability, but also own transport facilities, available for research.

My profound and never ending love to my family, Paola, Gabriele, and Vittoria, my first supporters in all my choices, my boundless source of energy and love.

To Anna and Gabriele, my wonderful parents, who simply love me whatever would happen.

To Gabriella, my sister, who taught me that coherence, integrity and hard work are the main attributes to achieve any goal.

Luigi 